FERMILAB-TM-1719

\title{
Procedures for Application of Don Cossairt's CASIM Calculations in TM-1140 to Bulk Shielding
}

\author{
Peter H. Garbincius \\ Fermi National Accelerator Laboratory \\ P.O. Box 500 \\ Batavia, Illinois 60510
}

February 1991 

Procedures for Application of Don Cossairt's CASIM Calculations
in TM-1140 to Bulk Shielding

Peter H. Garbincius

February, 1991

As part of the methodology documentation for the site-wide radiation shielding assessment, these two related notes were written showing how to apply the CASIM calculations of TM-1140 to determine required shielding for various beam intensities and steel-soil composites.

These notes have been reviewed by the Fermilab ES\&H Section and approved for use in evaluating shielding requirments.

file: shield_tm.txt 
Application of Don Cossairt's CASIM Calculation (TM-1140) to Bulk Shielding at Lower Intensities.

Peter H. Garbincius

30 January 91

The following note and plots uses the hadronic shower energy deposition CASIM monte carlo calculations of Don Cossairt (TM-1140) to extend the shielding depth criteria to low intensity primary beams (say after a pin-hole attenuating collimator) or to secondary beams. The overburden criteria for shielding of the accidental beam loss of primary beams is specified in the two notes:

"Generic Shielding Criteria for Compliance with Chapter 6 of the Fermilab Radiation Guiden, by Don Cossairt, 11 December 91,

and

"Criteria to be used by the Safety Section in the Evaluations of Shielding Adequacy for the Fixed Target Beamlines", by Don Cossairt, 2 January 91, as approved by Dennis Theriot and John Peoples.

The question arose as to the methodology to be followed for lower intensity and lower energy secondary beams. The data does exist in TM-1140 and this note is intended to provide a readily accessible and usable form of this data.

I had asked Don Cossairt whether we can simply use the rule of thumb of a factor of 10 attenuation for each additional 3 feet of dirt shielding. Don's response was that this rule was not applicable at all depths of the shower and that some calculation would have to demonstrate the adequacy of the shielding at the specfic depth and hadron beam intensity.

Here's how I prepared these calculations.

The data presented by Cossairt in $T M-1140$ is in units of number of stars per cubic centimeter per proton in a dirt shield. The Fermilab Radiation Guide limits (Chapter 6, Tables 1, 2A, and 28) are in units of $\mathrm{mrem} / \mathrm{hr}$ or mrem/pulse. For (uncompacted) thick soil shields, the Fermilab Radiation Guide, Chapter 13, Table 1 , lists the conversion factor as:

\section{$10.8 \mathrm{micro-rem} / \mathrm{star} / \mathrm{cm} * * 3$.}

Just to show how this conversion term comes about, I will discuss some of the references. In order to convert we use the Table 2 (page 9) of $P$. Collon (TM-664) for concrete (similar density to earth). For a person standing behind a concrete shield, the Entrance Absorbed Dose is $1.5 \mathrm{micro-rad} / \mathrm{star} / \mathrm{cm} * 33$. After applying the appropriate Quality Factor of 5.3 (TM-664, Table 2), the Maximum Dose Equivalent is $9 \mathrm{micro-rem} / \mathrm{star} / \mathrm{cm} * * 3$, the conversion factor for concrete shields. The book by A. Van Ginneken and M. Awschalom, High Energy Particle Interactions in Large Targets, vol 1. Hadronic Cascades, Shielding, Energy Deposition, 1975, page 49, also shows this same conversion factor for concrete and gives, by CASIM calculation, that the average Quality Factor is a constant for shower depths beyond about 2 meters.

The data presented by Cossairt in TM-1140 is graphical, contours of constant star density per proton in dirt shields for various loss geometries. I had a designer extend horizontal lines parallel to the z-axis of the plots to the $y$-depth scale at a height corresponding to the maximum of a given contour. See the example in Figure 0 . This length along the $y$-axis was measured and scaled to the depth scale, producing a correlation between the maximum shower 
depth and the associated contour in $10 * *-$ ? stars $/ \mathrm{cm} * * 3 /$ proton. A table was made for this geometry and Cossairt plot showing contour (stars/cm**3/proton), and maximum shower depth (ft-dirt equivalent, above the enclosure or pipe). This contour value was scaled by $10.8 \mathrm{micro-rem} / \mathrm{star} / \mathrm{cm} * * 3$ for soil to give the countour value in units of mrem/proton. This was plotted as a function of depth, for example, in Figure 1. Sorry for the wavy-ness of the curves, but that's how Don's contours read.

Possibly useful, but one more transformation will make it much more useful. He would like to get the maximum number of protons ( $N=$ protons/pulse) that can be allowed to be accidently lost in a particular geometry for a given amount of earth shielding transversely, and for given protection classification. This protection classification depends on whether minimal occupancy, locked gates, etc.

For no interlocked detectors, if we desire the maximum loss to produce a radiation field of $B \mathrm{mrem} / \mathrm{hr}$, then the maximum number of protons allowed per pulse is given by

$$
\begin{aligned}
& \mathrm{N}(\max \text { protons } / \mathrm{pulse})=B(\mathrm{mrem} / \mathrm{hr}) \\
& \text { A (mrem/proton)* } 60 \text { pulses/hr }
\end{aligned}
$$

where the factor $A$ is loss point and shield geometry dependent and is obtained from the above described contours and tables.

For use with interlocked detectors, if we desire the maximum loss to produce radiation level of $C \mathrm{mrem} / \mathrm{pulse}$, then the maximum number of protons allowed per pulse is given by

$$
N\left(\text { max protons/pulse) }=\frac{C \text { (mrem/pulse) }}{A \text { (mrem/proton) }}\right.
$$

with same $A$ as above.

Armed with all of this, we then can consider, for example, the case of no interlocked detectors, minimal occupancy. The value $B$ is $10 \mathrm{mrem} / \mathrm{hr}$ for accidental losses, according to the Fermilab Radiation Guide Table $2 A$. For $1 \mathrm{TeV}$ protons lost on a magnet 3 feet below the ceiling of the enclosure, we can then plot the curve in Figure 2 using the mrem/proton value of $A$ for a given shield depth from Figure 1 for that geometry. Remember that these were generated from Cossairt's contours for this geometry.

Thus we have a curve showing the maximum allowed number of protons per pulse for minimum occupancy, with no interlocked detectors, for accidental losses on a magnet, 3 feet below the enclosure ceiling, as a function of the equivalent earth overburden. Big deal, how does this help me? Just watch!

0.K. let's assume as Cossairt did, the full acclerator at 2 E13 per pulse. Simply read off the required dirt as 19 feet. Let's now consider other protection classifications. I'll only use the most common. You can easily see how this is done in Figure 3 .

Description

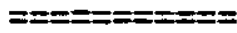

minimum occupancy

locked fences \& signs
Rad Limit

=ニ=ニニ=ニ

$10 \mathrm{mrem} / \mathrm{hr}$

$500 \mathrm{mrem} / \mathrm{hr}$
Scale Factor

\section{=ニ==:====ニ=}

1

- we just did this example

$1 / 50$ 
min. occ. \&

interlocked detectors $2.5 \mathrm{mrem} / \mathrm{pulse}$

$1 / 15 \quad$ - note factor of 60 remove

locked fences, signs \&

interlocked detectors

$50 \mathrm{mrem} / \mathrm{pulse}$

$1 / 300$ - note factor of 60

So for minimal occupancy, 2 E13 requires 19.2 feet from graph (Cossairt says $19 \mathrm{ft}$. )

For locked fences and signs, use $2 \mathrm{E} 13 * 1 / 50=4 \mathrm{E} 11$, and look up on graph that this requires 14.9 feet (Cossairt says $15 \mathrm{ft}$ ).

For minimum occupancy with interlocked detectors, use $2 \mathrm{E} 13 * 1 / 15=1.33 \mathrm{E} 12$ and use graph to find a required 16.2 feet (Cossairt says $16 \mathrm{ft}$ ).

For locked fences and signs with interlocked detectors, use

2 E13 $* 1 / 300=6.7$ E10 and use graph to find 13 feet required

(Cossairt says $13 \mathrm{ft}$ ).

So it seems to work. We are finding the dirt needed for $1 \mathrm{TeV}$ loss at a given intensity using the actual contours as a function of depth, not as a rule of thumb!

If you want to know how much earth shielding is required for a 1 E9 particles/pulse secondary pion beam at $400 \mathrm{GeV}$ for minimal occupancy, no interlocked detector, simply read off from Figure 2 or 3 the required dirt depth of 6.5 feet of earth equivalent.

Please note that the relative amount of allowed intensity at $400 \mathrm{GeV}$ is approximately twice that allowed at $1 \mathrm{TeV}$ for all examples studied.

Earth vs. Intensity Graphs for the minimal occupancy, no interlocked detector case are enclosed for the three accidental loss conditions:

Fig 2: $1 \mathrm{TeV}$ and $0.4 \mathrm{TeV}$ loss on magnet, 3 feet below enclosure ceiling

Fig 4: $1 \mathrm{TeV}$ and $0.4 \mathrm{TeV}$ loss on thin pipe, $3 \mathrm{ft}$ below enclosure ceiling

Fig 5: $1 \mathrm{TeV}$ and $0.4 \mathrm{TeV}$ loss on berm pipe

Finally, I compile the benchmark between this "interpolation scheme" and Cossairt's criteria (in parenthesis) for primary beam accidental losses.

$\begin{array}{llll}\text { PHG (Cossairt) } & \begin{array}{l}\text { magnet } \\ ===========\end{array} & \begin{array}{l}\text { thin pipe } \\ ======\end{array} & \begin{array}{l}\text { berm pipe } \\ =======\end{array} \\ \text { minimal occupancy } & 19.2^{\prime}\left(19^{\prime}\right) & 17.6^{\prime}\left(17^{\prime}\right) & 20.8^{\prime}\left(21^{\prime}\right) \\ \begin{array}{l}\text { locked fences \& signs } \\ \text { minimal occupancy \& } \\ \text { interlocked detectors }\end{array} & 14.9^{\prime}\left(15^{\prime}\right) & 13.4^{\prime}\left(13^{\prime}\right) & 16.2^{\prime}\left(16^{\prime} 5^{\prime}\right) \\ \begin{array}{l}\text { locked fences \& signs \& } \\ \text { interlocked detectors }\end{array} & 16.2^{\prime}\left(16^{\prime}\right) & 14.8^{\prime}\left(14^{\prime}\right) & 17.2^{\prime}\left(17^{\prime}\right) \\ & 13.0^{\prime}\left(13^{\prime}\right) & 11.1^{\prime}\left(11^{\prime}\right) & 14.1^{\prime}\left(14^{\prime}\right)\end{array}$

In closing, I warn the users to consider the DC loss points such as target stations where even more stringent limits of Table 1 of the Rad Guide apply. 
Fig. 0 Cossairt star density contour map for $1 \mathrm{TeV}$ beam striking magnet.

$300 \quad 200 \quad 400 \quad$ DEPTH $(\mathrm{cm}$.

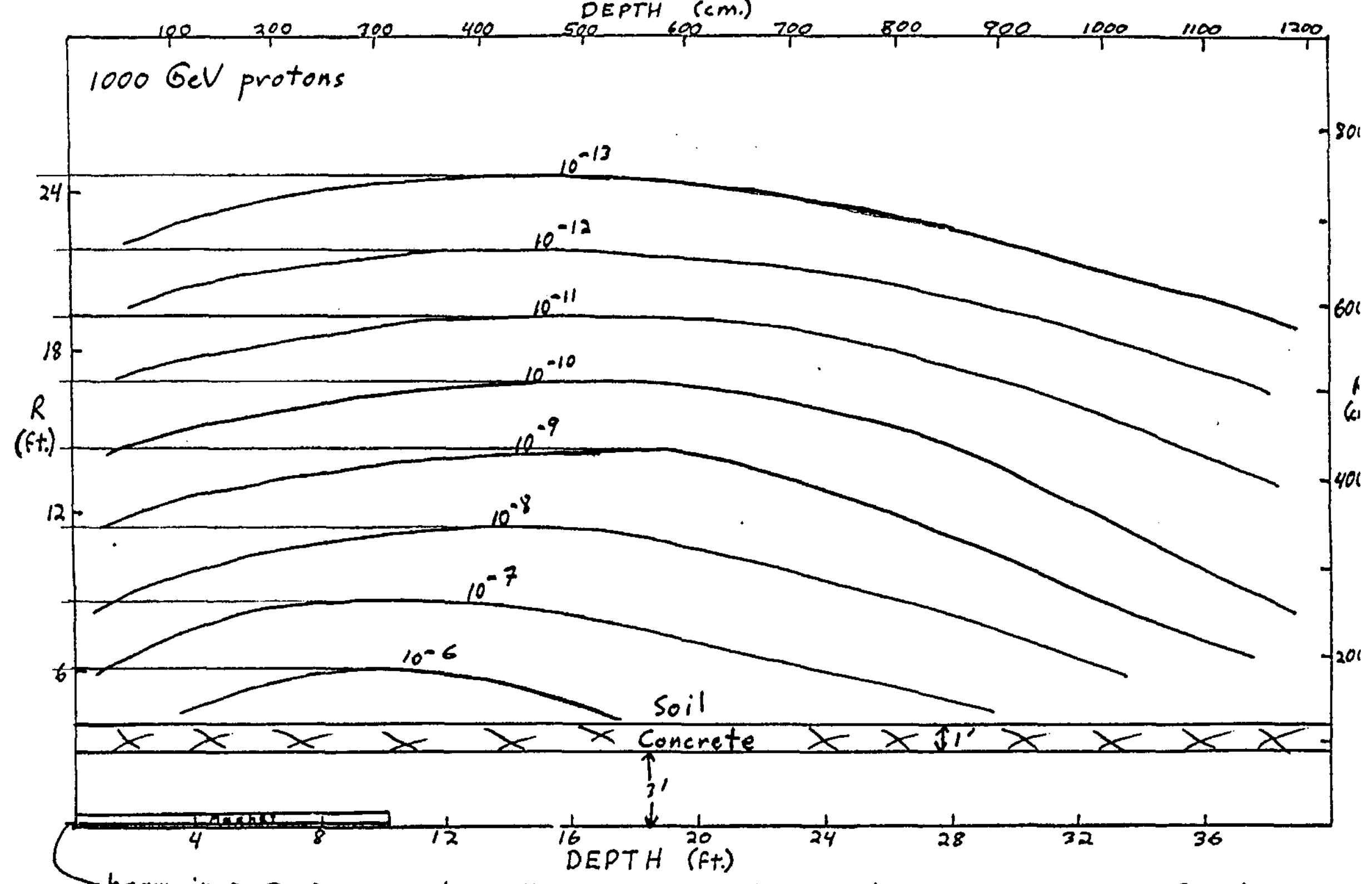

beam in a $\sigma=2 \mathrm{~mm}$ spot trikes a magnet

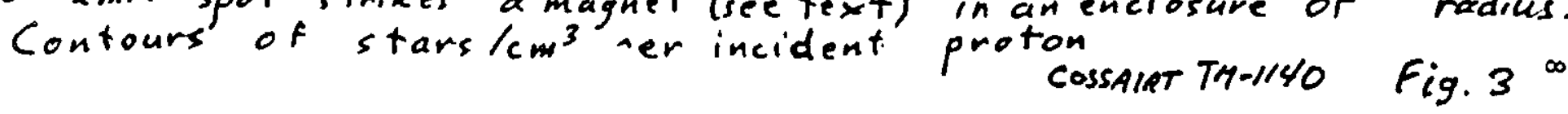


Fig 1. Beam Striking Magnet 3 Feet from Ceiling of Enclosure Reference: TM-1140, Fig 1 \& 3.

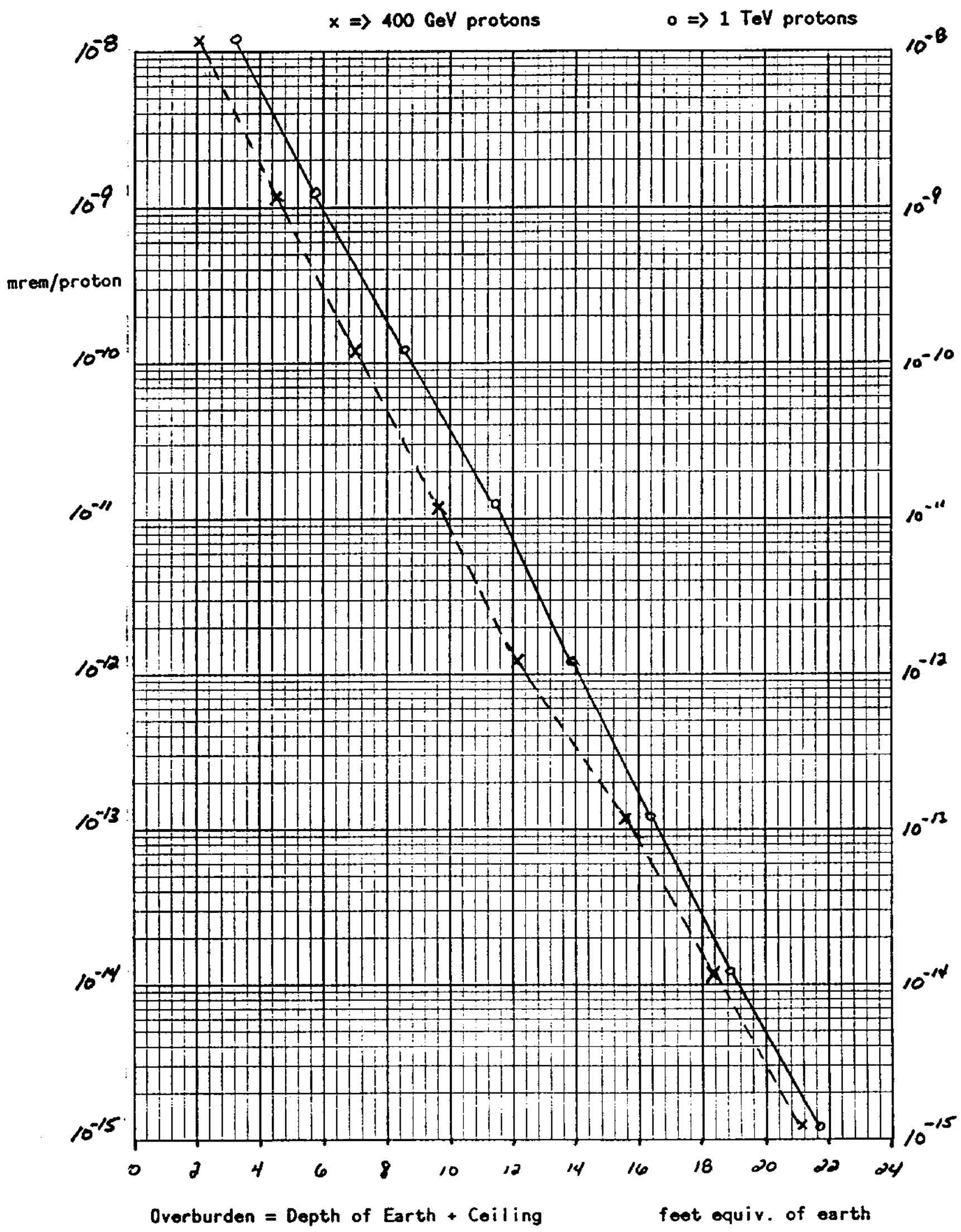


Fig. 2. Beam ACCIDENTLY Striking Magnet 3 Feot from Coiling of Enclosure Minimum Occupancy - No Inter locked Detectors

Rof.: TM-1140, Fig 1 \& 3, Formilab Rad. Guido Ch. 6, Table $2 A$.

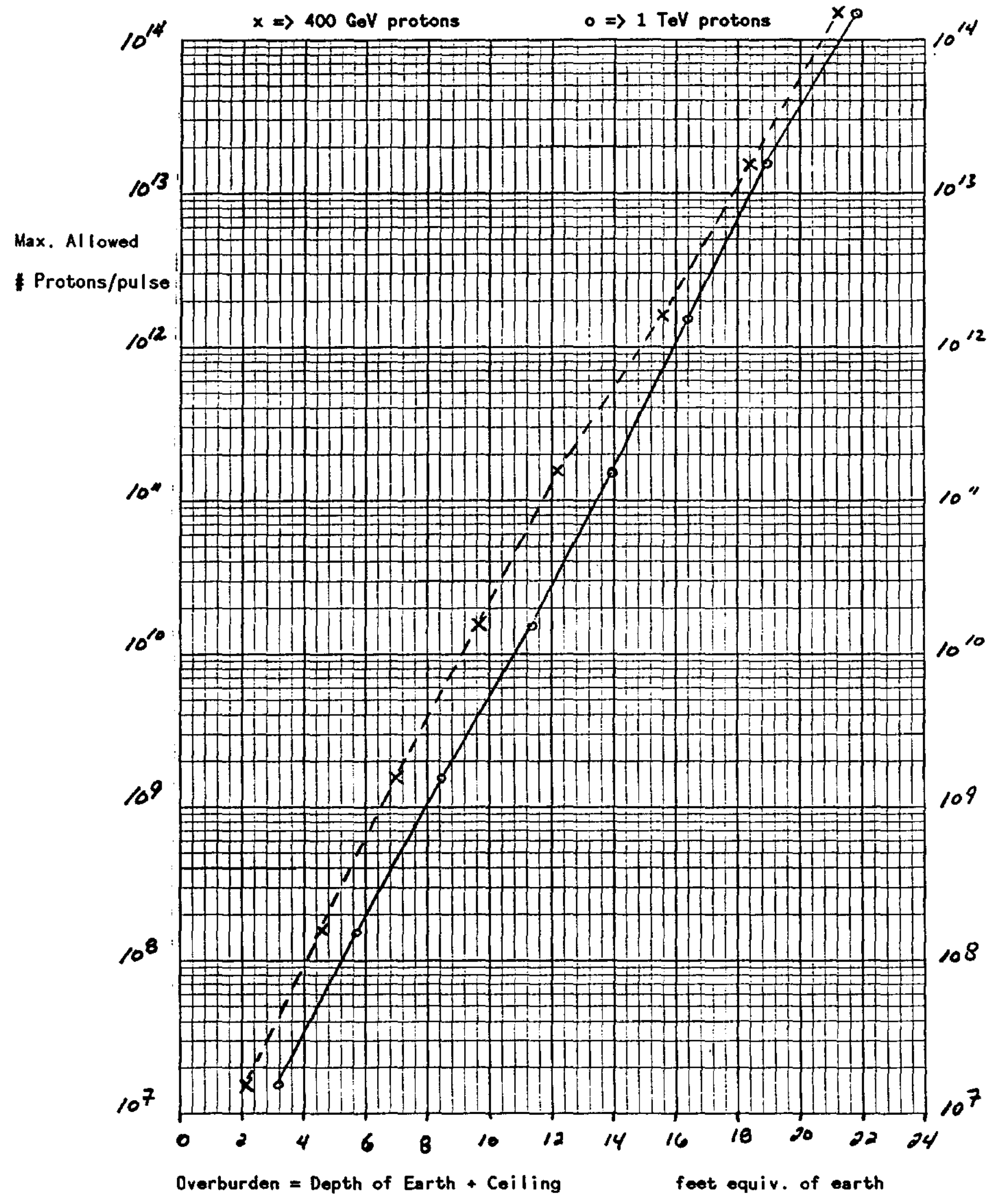


Figure 3. Beam ACCIOENTLY Striking Magnet 3 Feet from Ceiling of Enclosure No Interlocked Detectors Ref.: TM-1140, Fig. 1 \& 3, Fermilab Rad. Guide Ch. 6, Table $2 A$.

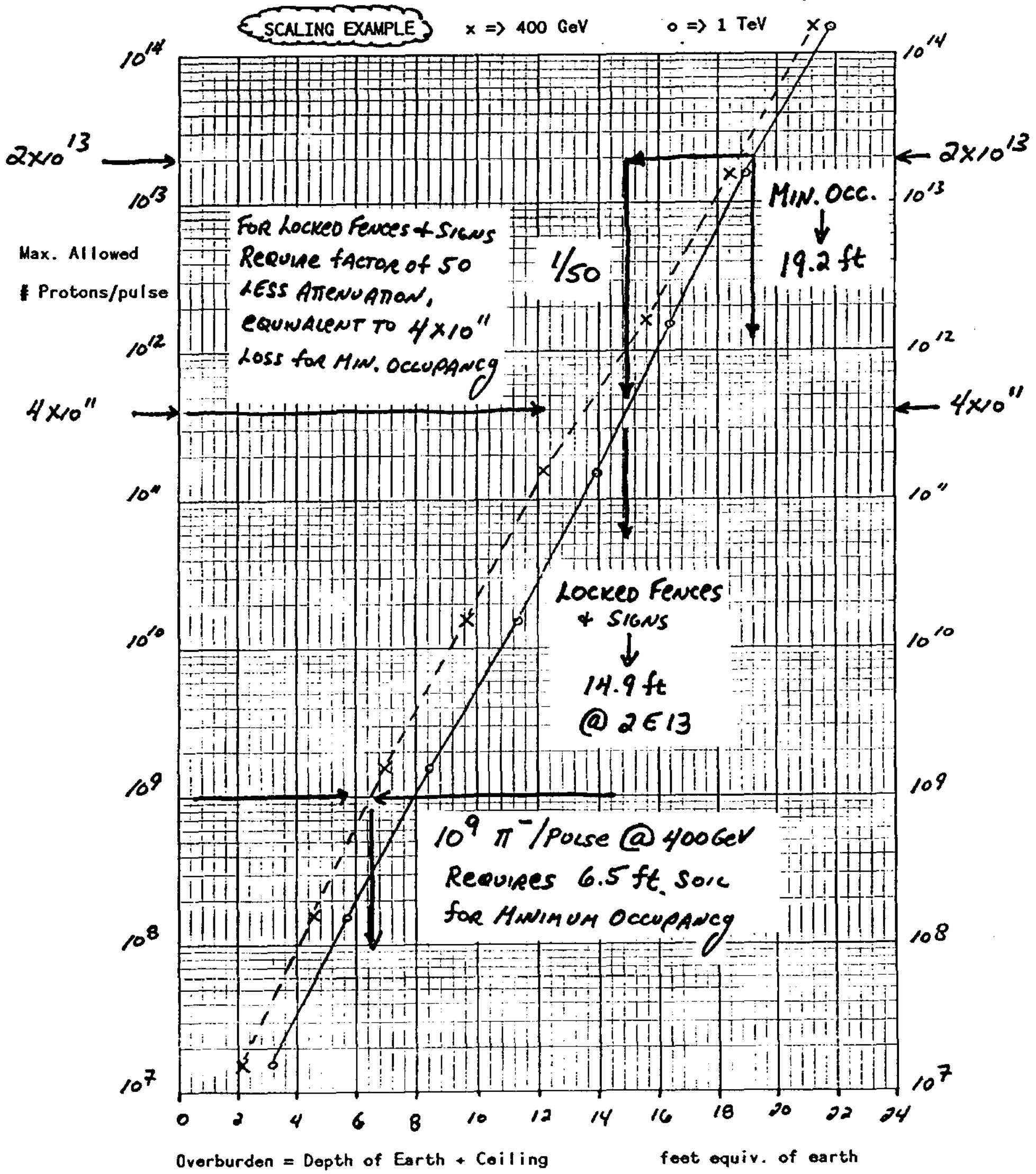


Fig. 4. Beam ACCIDENTLY Striking Thin Beam Pipe $3 \mathrm{ft}$ from Ceiling of Enclosure Minumum Occupancy - No Inter lockod Detectors

Ref.: TM-1140, Fig. 9 \& 11, Fermilab Rad. Guido, Ch. 6, Table $2 A$.

$x \Rightarrow 400 \mathrm{GeV} \quad 0 \Rightarrow 1 \mathrm{ToV}$

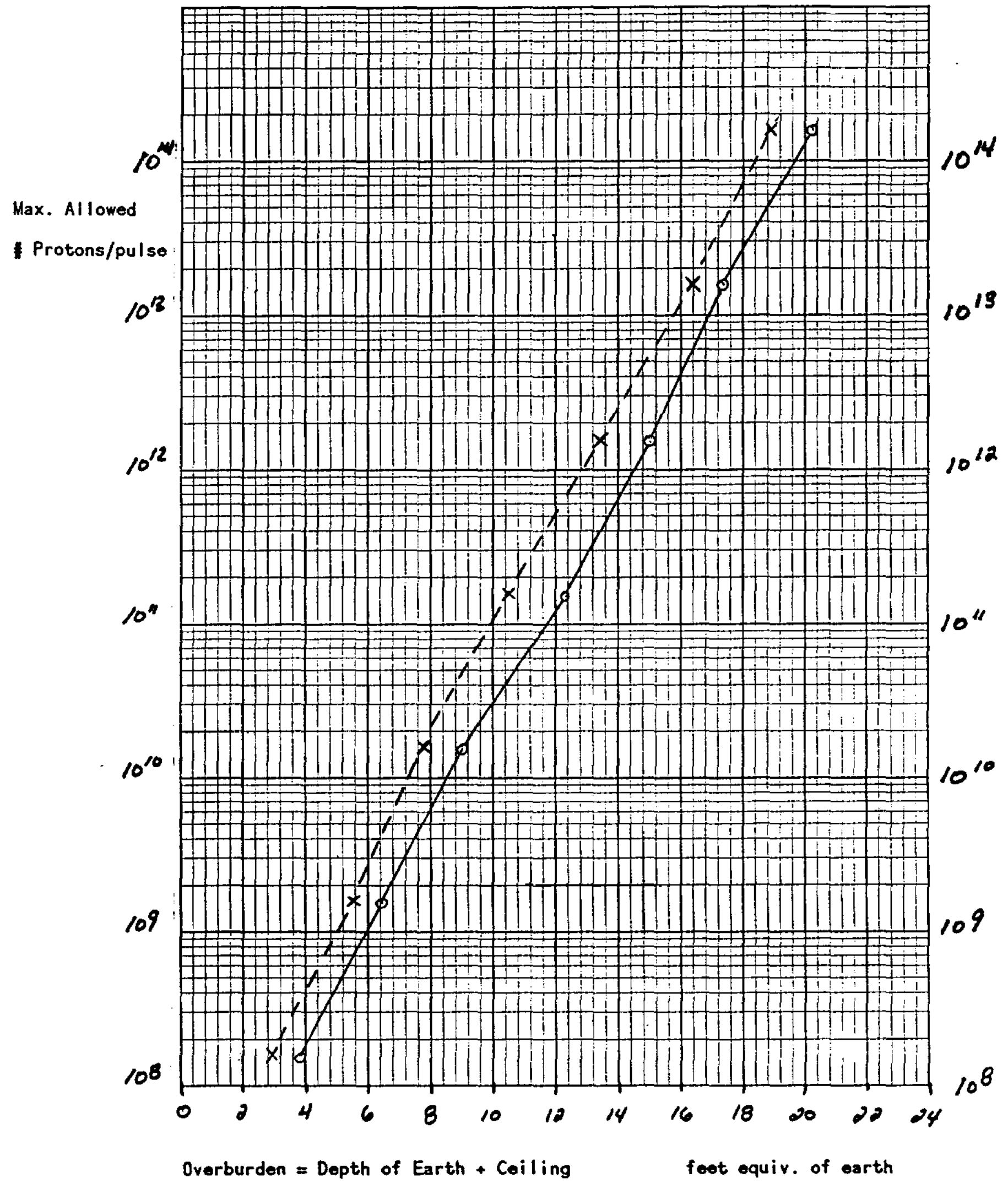


Fig. 5. Beam ACCIDENTLY Striking Buried Pipe

Minimum Occupancy - No Interlocked Detectors
Ref : TM-1140, Fig. 17 \& 18 , Fermilab Rad. Guide, Ch. 6, Table 2 A.

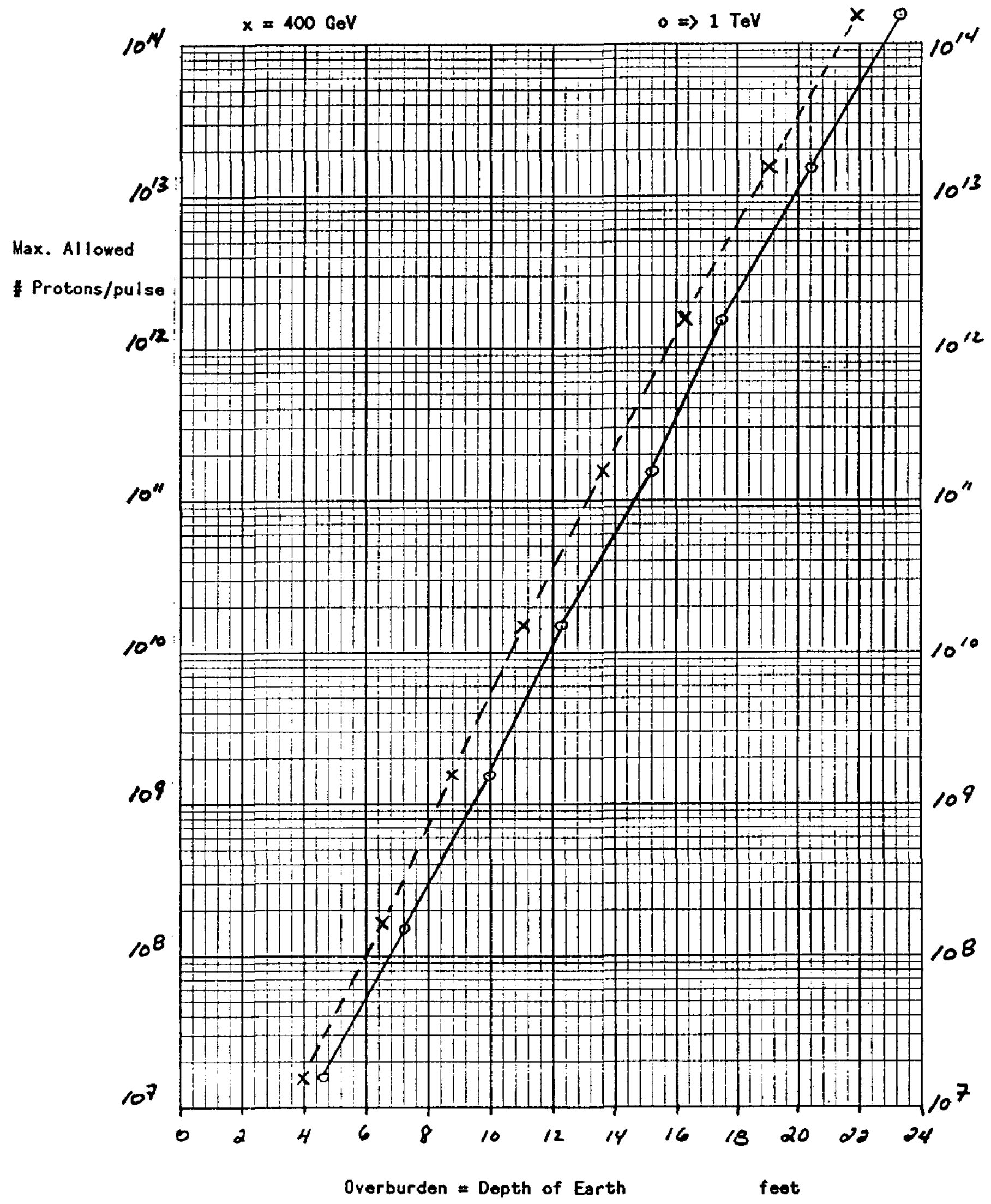


Discussion of Earth-Equivalent of Buried Steel Shielding

Peter H. Garbincius

17 February 91

This note continues the use of the hadronic shower energy deposition CASIM monte carlo calculations of Don Cossairt $(\mathrm{TM}-1140)$ to study the earth equivalent value of buried steel. In the past, the rule of thumb was that one foot of steel had the star density attenuation equivalent of three feet of earth.

As in my note of 30 January 91, I found the maximum of the star density contours for a $1 \mathrm{TeV}$ proton beam striking a buried berm pipe without (TM-1140, fig. 18) and with (TM-1140, fig. 20) an additional 3 feet of steel buried 1 foot above the top of the pipe. The berm pipe case is considered since it represents a common usage under roads and access areas in the experimental areas.

The star densities at the outer edge of the composite shield (sum of height of earth plus steel) are shown in Fig. 6. If the total height of shielding is, for example, 16 feet above the top of the pipe, then for 3 feet of steel plus 13 feet of soil the star density is $3.8 \mathrm{E}-13$ stars $/ \mathrm{cm} * * 3$ per proton, while for 16 feet of soil without steel, the star density is 4 E-11 stars/cm**3 per proton. The additional attenuation obtained by replacing these 3 feet of earth by 3 feet of deeply buried steel is a factor of 100 at this representative shield height.

We can continue to find the earth-equivalent of steel in the following way. Using figure 6 , we can read off a given decade star density contour the total number of feet of pure earth and the total number of feet of earth plus 3 feet of steel necessary to get this star density. This equivalency is not a constant and depends on the total number of feet of dirt above the steel.

Sample calculation: consider the star density of 1 E-11 stars/cm**3 per proton. This level is obtained with either $17.65^{\prime}$ earth or $11.98^{\prime}$ consisting of $8.98^{\prime}$ earth plus $3^{\prime}$ steel. Thus equivalent shielding is obtained from:

$$
\begin{aligned}
& 17.65^{\prime} \text { earth } \Leftrightarrow 8.98^{\prime} \text { earth }+3^{\prime} \text { steel } \\
& 8.67^{\prime} \text { earth } \Leftrightarrow 3^{\prime} \text { steel } \\
& 2.89^{\prime} \text { earth } \Leftrightarrow 1^{\prime} \text { steel }
\end{aligned}
$$

You gotta be careful how you use these numbers. In particular, there are two factors in getting the dose at any point, namely the attenuation and the distance (e.g. for isotropic point sources with no attenuation, the dose scales as $1 / R * * 2$ solid angle acceptance). This calculation, both (ASIM and the hand analysis, automatically includes the effect of both of these factors. The user must be careful in using these conversion factors in the same definition as used in the calculation. Finally, when using steel, the user must remember to add at least some earth or concrete beyond the steel to take into account the low-attenuation window for low energy neutrons for steel. 
Continuing for other star density levels:

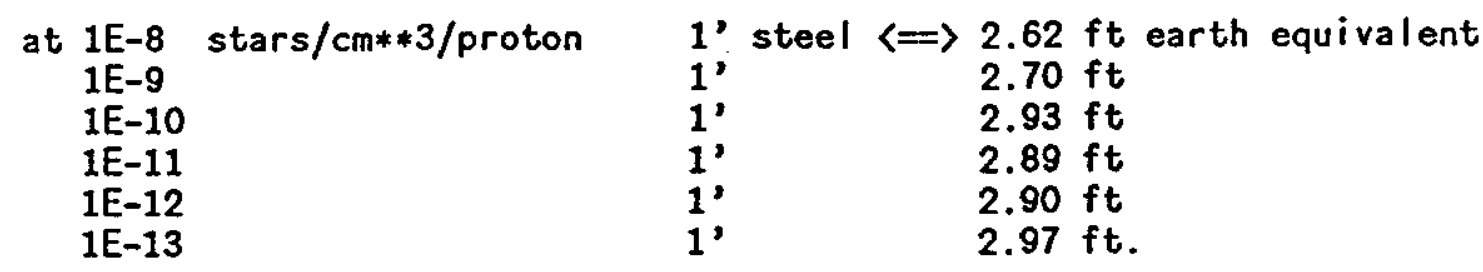

I hope these calculations are useful.

Peter

Additional comments:

Gerry Dugan has distributed a note entitled, "Shielding Scaling Calculations" dated 7 February 91 . In this note, he follows much the same methods $I$ used in my note of 30 January 91 . Gerry has parameterized these methods to allow calculation of the shielding required for a given dose per proton for a given protection class. It seems more complete and more readily useful for calculation than my note. Gerry also includes a discussion of beam energy scaling behavior.

One item that is in the same spirit as this note is his parameterization of his curve in Fig. 2 which says that a factor of 10 reduction in dose can be obtained by the addtion of 2.745 feet of soil at $1 \mathrm{TeV}(2.665$ feet at $400 \mathrm{GeV})$. Again, the rule of thumb: a factor of 10 attenuation by 3 feet of soil is verified and shown to be slightly conservative.

Peter

file: steel_shield.txt 
Fig. 6. 1 TeV Beam Striking Buried Pipe

14 Feb 91

$0 \Rightarrow$ Earth only, No Steel, ref: TM-1140, fig. 18

$x \Rightarrow$ Earth +3 ft Buried Steol, rof: TM-1140, fig. 20.

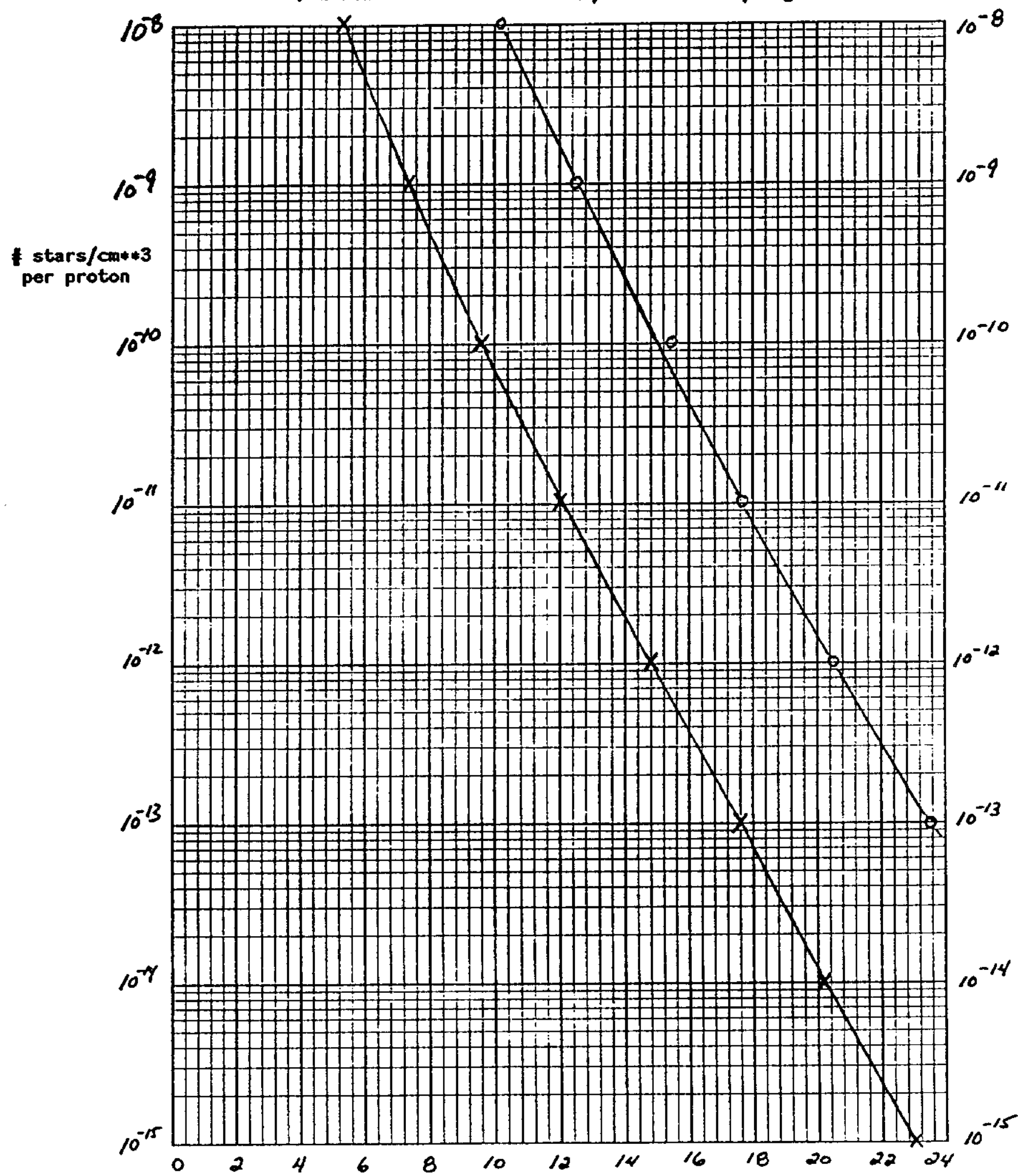

Total Meight of Shiolding above top of struck beam pipe foet including earth and stool 